\title{
The Fitting Strength between Ceramic and Metal with the Use of a Bimetal Shrink Fitter at Elevated Temperature*
}

\author{
Isami NITTA, ${ }^{* *}$ Katsumi NAKASHIZUKA** \\ and Toshiaki HARA**
}

\begin{abstract}
The shrink fit between a ceramic shaft and a metal ring with the use of a bimetal shrink fitter has been developed in this paper. The fitting strengths of the shrink-fitted assemblies were measured from room temperature to $600^{\circ} \mathrm{C}$. The contact pressures between the shafts and the shrink fitters of bimetal were also calculated. The ceramic shaft was $\mathrm{Al}_{2} \mathrm{O}_{3}$ or $\mathrm{Si}_{3} \mathrm{~N}_{4}$. The shrink fitter was a bimetal of SUS304 and SUS403. The outer ring was SUS403. It was shown from the calculations that the shrink-fitted assembly using the bimetal shrink fitter was somewhat weaker than that using the monolithic SUS304 shrink fitter when the thickness of the shrink fitter in the radial direction was over $6 \mathrm{~mm}$. The shrink-fitted assembly using the bimetal shrink fitter was approximately $3 \mathrm{MPa}$ stronger than that using the monolithic SUS304 shrink fitter at $600^{\circ} \mathrm{C}$ when the thickness of the shrink fitter in the radial direction was $4 \mathrm{~mm}$. The fitting conditions under which the shrink-fitted assembly using the bimetal shrink fitter was stronger than that using the monolithic SUS304 shrink fitter were discussed.
\end{abstract}

\section{Key Words : Fixing Element, Ceramics, Shrink Fit, Shrink Fitter, Bimetal, Elevated Temperature, High Temperature, Slit, Strength}

\section{Introduction}

Shrink fitting is a suitable technique for joining ceramic and metal elements because of the low thermal stress caused by possible microslip at the joint interface ${ }^{(1),(2)}$. Its good shaft location makes it easy to include the shrink fit into mass production steps.

A shrink-fitted assembly between a ceramic shaft and a metal cylinder, however, could be used only up to $200^{\circ} \mathrm{C} \sim 300^{\circ} \mathrm{C}$ because of the great difference in their coefficients of thermal expansion ${ }^{(3),(4)}$.

In a previous paper ${ }^{(5)}$, shrink fitting with the use of a shrink fitter which contains slits in a radial direction was devised to improve the fitting strength at elevated temperature. It was shown that the fitting strength using the shrink fitter did not decrease even at $600^{\circ} \mathrm{C}$.

The shrink fitter must be thicker in the radial direction when the coefficients of thermal expansion of the shaft and the cylinder differ greatly. Thus the next challenging problem is to minimize the thickness of the shrink fitter in the radial direction. One of the

* Received 16th July,1990. Paper No.89-0249A

** Mechanical Engineering, Faculty of Engineering, Niigata University, Igarashi 2 Nocho 8050, Niigata 950-21, Japan methods which solve this problem not using material which has an extremely high or low coefficient of thermal expansion is to use a shrink fitter of bimetal structure.

In this paper, the experiments of shrink fits between ceramic shafts and metal rings were carried out using the bimetal shrink fitters in order to thin the dimensions of the shrink-fitted assemblies in the radial direction. Conditions under which the use of the bimetal shrink fitter is better for stronger assembly than that of the monolithic shrink fitter were also discussed theoretically and experimentally.

\section{Bimetals and Shrink-Fitted Assemblies}

The shrink-fitted assembly considered in this paper is schematically shown in Fig. 1. An interface between the shaft and the shrink fitter in Fig. 1 is referred to as an inner interface and another interface between the shrink fitter and the outer ring is referred to as an outer interface. There are some slits in the bimetal shrink fitter (three slits in Fig. 1).

A bimetal is a clad of two kinds of metals. The bimetals have been used to detect and control temperature and to protect circuits ${ }^{(6)}$. It seems, however, that there are few examples of the use of the bimetal to join structures which require strength ${ }^{(7)}$ 
The bimetals used in this paper are made by brazing SUS304 and SUS403. The coefficient of thermal expansion of SUS304 is larger than that of SUS403. Thus the radius of curvature increases with temperature for the bimetal shrink fitter which consists of SUS304 inside and SUS403 outside (Fig. 2 (a)). In Fig. 2(a), the deformation seems to be two-dimensional but the actual deformation is threedimensional. Hereinafter, this type of bimetal is referred to as a $\mathrm{BO}$ (bending outward) type. Another type of bimetal is referred to as a $\mathrm{BI}$ (bending inward) type (Fig. 2(b)).

Contact conditions of the assemblies at elevated temperature are also shown in Fig. 2(a) and Fig. 2 (b) for the BO and $\mathrm{BI}$ types, respectively. In these figures, only one piece of the shrink fitter is shown. For the BO type, it is predicted that the shrink fitter comes into contact with the shaft at the center of one piece of the shrink fitter and with the outer ring at slits, and vice versa for the BI type.

The interference of the traditional shrink fit between the ceramic shaft and the metal ring decreases at elevated temperature because of the great difference in their coefficients of thermal expan-

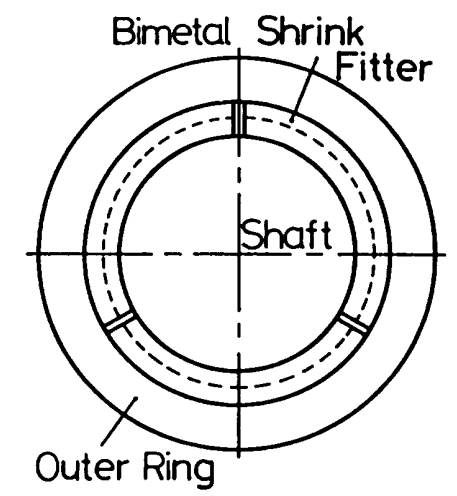

Fig. 1 Shrink fit with the use of the bimetal shrink fitter sion. The method proposed in the previous paper ${ }^{(5)}$ was to make up for the decrease in the interference at elevated temperature by using the thermal expansion of the shrink fitter in the radial direction. On the other hand, the curviform deformation of the bimetal shrink fitter shown in Fig. 2(a) or Fig. 2(b) makes up for the decrease in the interference at elevated temperature.

\section{Calculations of Strength of the Assemblies}

The deformations of the assemblies were assumed to be two-dimensional, as shown in Fig. 1. The distributions of the contact pressures were calculated by a method of point matching. The process of calculation was described in detail in a previous paper $^{(8)}$. The coefficients of friction at the inner and outer interfaces were also assumed to be 0 . The interferences at the inner and outer interfaces were $7.5 \mu \mathrm{m}$ and $7.5 \mu \mathrm{m}$, respectively, in radius and the total interference in diameter was $30.0 \mu \mathrm{m}$. The width of the slits was assumed to be $0 \mathrm{~mm}$.

The materials of the shaft and the outer ring were $\mathrm{Al}_{2} \mathrm{O}_{3}$ and SUS403, respectively. Their Young's moduli, Poisson's ratios and coefficients of thermal expansion were the same values as in the previous paper $^{(8)}$. The dimensions of the assembly, which are 25 $\mathrm{mm}$ in shaft diameter, and $33 \mathrm{~mm}$ and $41 \mathrm{~mm}$, respectively, in inner and outer diameters of the outer ring, are referred to as $\phi 25-\phi 33-\phi 41$. The distributions of the contact pressures at only the inner interfaces were shown because the fitting strengths at the inner interfaces were measured in the experiments.

\section{Results of Calculations}

Figure 3 shows the distributions of the contact pressures at the inner interface of the assembly which uses the shrink fitter of the BO type and has 3 slits.
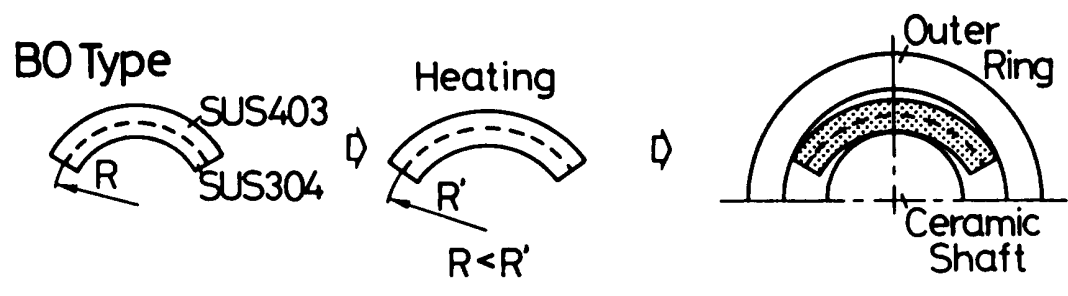

Fig. 2(b) Curviform deformation of the shrink fitter of the BI type
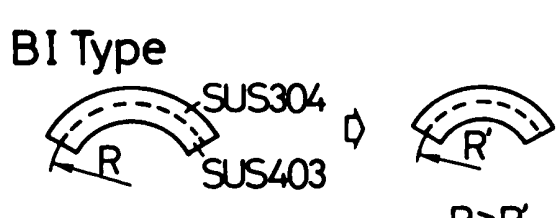

Q

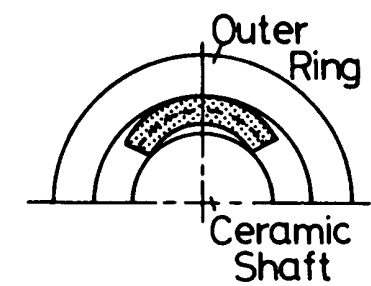

Fig. 2(a) Curviform deformation of the shrink fitter of the BO type 
Figure 4 shows the distributions of the contact pressures for the shrink fitter of the BI type. The abscissas in those figures represent the position in the circumferential direction : $\theta=\pi / 3$ at the slit and $\theta=0$ at the center of one piece of the shrink fitter. In both figures, the thickness of the shrink fitter in the radial direction was $4 \mathrm{~mm}$ and the ratio of the thickness of SUS304 to that of SUS403 was 1: 1. In Fig. 3 for the BO type, the region where the contact pressure was 0 , spread with temperature from $\theta=\pi / 3$ to $\theta=0$. In Fig. 4 for the BI type, the contact pressure at the slit conversely increased with temperature and the contact pressure at $\theta=0$ decreased gradually. It can be seen that the contact condition at the inner interface in Fig. 3 is similar to that of the model shown in Fig. 2(a) at elevated temper: ure. The contact condition at elevated temperatise in Fig. 4 is, however, more complicated than that of the model shown in Fig. 2(b). It could be thought that the ceramic shaft at the slit

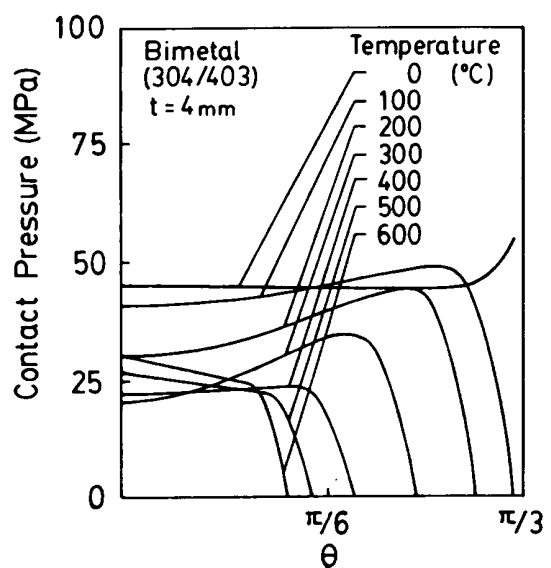

Fig. 3 Relationships between the contact pressures and the circumferential position at the inner interface (BO type; thickness ratio of SUS304 to SUS403, $1: 1 ; \phi 25-\phi 33-\phi 41$; number of slits, $3 ; \mathrm{Al}_{2} \mathrm{O}_{3}$ )

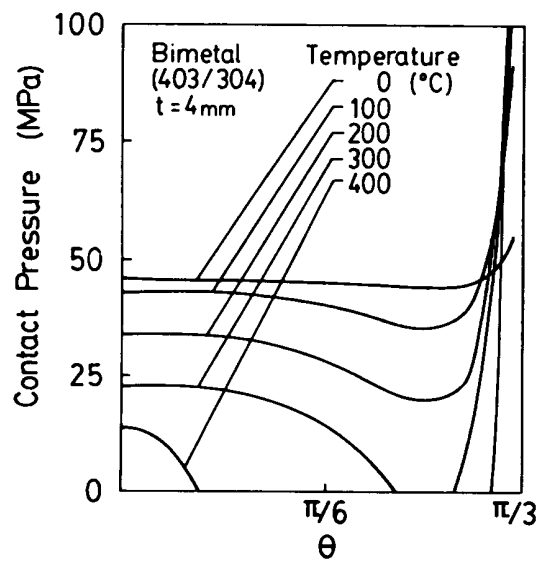

Fig. 4 Relationships between the contact pressures and the circumferential position at the inner interface (BI type; thickness ratio of SUS304 to SUS403, $1: 1 ; \phi 25-\phi 33-\phi 41$; number of slits, $3 ; \mathrm{Al}_{2} \mathrm{O}_{3}$ ) would fracture because of the stress concentration at this point.

Figure 5 shows the relationship between the ratio of thickness of SUS304 to that of the bimetal shrink fitter, $t$, in the radial direction and the shear strength at the inner interface, where $t=4 \mathrm{~mm}$. The shear strength was calculated by multiplying the mean contact pressure at the inner interface by the coefficient of friction 0.4 obtained experimentally. Zero and 1 in the abscissa show that the shrink fitters consist of only SUS403 and SUS304, respectively. It can be seen that the monolithic SUS304 shrink fitter gives the strongest assembly at each value of temperature up to $400^{\circ} \mathrm{C}$. This fact shows that the compensation for the decrease in the interference by the curviform deformation of the bimetal is not effective up to $400^{\circ} \mathrm{C}$. The bimetal shrink fitters of which the ratios of SUS304 were from $50 \%$ to $70 \%$, however, gave the strongest assemhlies at $600^{\circ} \mathrm{C}$. For the BI type, the bimetal shrink fitter of which the ratio of SUS304 was $50 \%$ gave the strongest assembly at $600^{\circ} \mathrm{C}$ as well. From these results, the bimetal shrink fitters of which the ratios of SUS304 to SUS403 were 1: 1 were used in the next calculations and the following experiments.

Figure 6 shows the shear strength-temperature relationships with the thicknesses of the bimetal shrink fitters in the radial direction : $2 \mathrm{~mm}, 4 \mathrm{~mm}$ and $6 \mathrm{~mm}$ for the BO type. The calculated values for the monolithic shrink fitters and the bimetal shrink fitters of the BO type are shown for each thickness. The shear strengths of both the monolithic and bimetal shrink fitters decreased at elevated temperature with thinner shrink fitters. When the thicknesses were 6 $\mathrm{mm}$, the shear strength of the monolithic shrink fitter

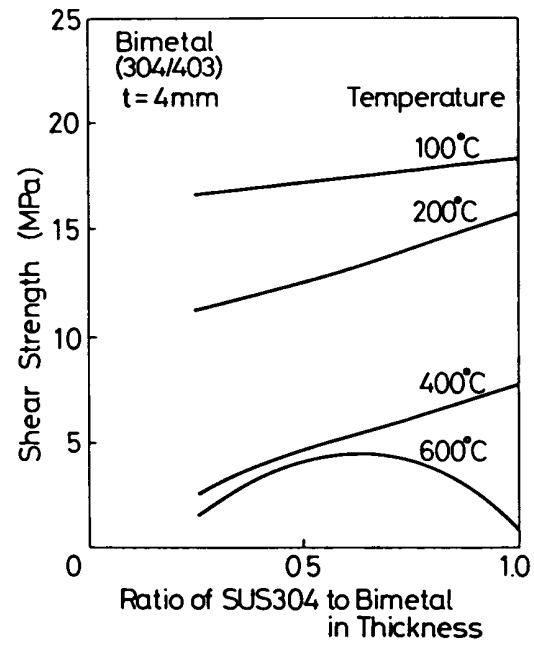

Fig. 5 Relationships between the shear strength and the thickness ratio of SUS304 to the shrink fitter in the radial direction (BO type ; $\phi 25-\phi 33-\phi 41$; number of slits, $3 ; \mathrm{Al}_{2} \mathrm{O}_{3}$ ) 
was greater than that of the bimetal shrink fitter if compared at the same temperature. When the thicknesses were $4 \mathrm{~mm}$, the shear strength of the bimetal shrink fitter was, however, greater than that of the monolithic shrink fitter approximately over $480^{\circ} \mathrm{C}$. When the thicknesses were $2 \mathrm{~mm}$, this changing of the shear strength occurs approximately at $420^{\circ} \mathrm{C}$. Thus it can be seen that not only the temperature at which the changing of the shear strength occurs but also the shear strength itself becomes lower with thinner shrink fitter in the radial direction.

Figure 7 shows the relationships between the shear strengths and the interferences in diameters which are $20 \mu \mathrm{m}, 30 \mu \mathrm{m}$ and $50 \mu \mathrm{m}$. The changing of shear strengths occurred at lower temperature and the assemblies using the bimetal shrink fitters of the BO type were stronger as the interference became smaller.

From the calculated results above, the conditions under which the assembly using the bimetal shrink fitter is stronger than that using the monolithic SUS304 shrink fitter are as follows.

(1) The shrink fitter is thin in the radial direction.

(2) The interference is small.

(3) The ratio of SUS304 to SUS403 in the thickness of the bimetal shrink fitter in the radial direction is approximately 1:1.

\section{Experimental}

\section{1 Specimens}

The materials were $\mathrm{Al}_{2} \mathrm{O}_{3}$ or $\mathrm{Si}_{3} \mathrm{~N}_{4}$ for the ceramic shafts and SUS403 for the outer rings. Materials for the bimetal shrink fitter were SUS304 and SUS403,

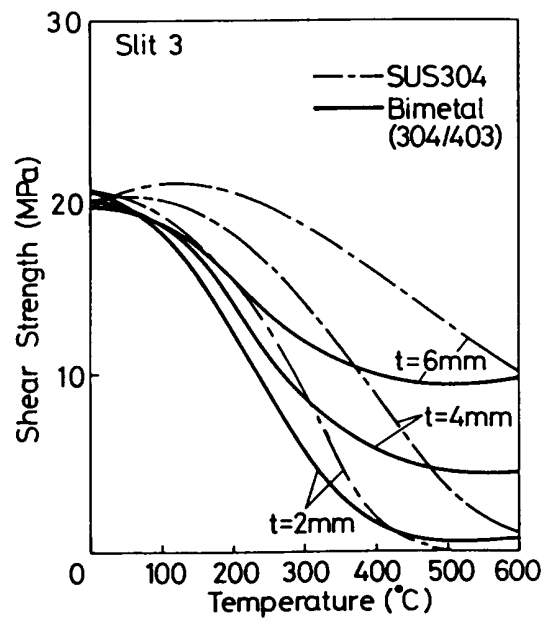

Fig. 6 Relationships between the shear strength and the temperature (comparison between the shrink fitters of the BO type and the SUS304 monolithic type for the various thicknesses in the radial direction ; number of slits, $3 ; \mathrm{Al}_{2} \mathrm{O}_{3}$ ) which were brazed to each other. The brazing was performed in Ar gas at $1100^{\circ} \mathrm{C}$ for $30 \mathrm{~min}$. The brazing foil was MBF20 made by Nippon Amorphous Metals Co., LTD. Thereafter the bimetals were annealed in air at $700^{\circ} \mathrm{C}$ for $1 \mathrm{hr}$. Then the bimetal shrink fitters were turned to the required dimensions.

Table 1 shows the shapes and the nominal dimensions of the bimetal shrink fitters and the outer rings. The width of the slit in the bimetal shrink fitter was $1 \mathrm{~mm}$. Table 2 shows Young's Modulus and Poisson's ratio at room temperature, and the mean coefficient of thermal expansion from $0^{\circ} \mathrm{C}$ to $648^{\circ} \mathrm{C}$ for each material. The maximum surface roughnesses $R_{\max }$ of the ceramic shaft and the metal ring were approximately $3 \mu \mathrm{m}$ and $7 \mu \mathrm{m}$, respectively. The interference in this experiment was calculated from the diameters of the shaft, the outer ring and the shrink fitter before being slit.

\subsection{Experimental procedures}

The specimens were cleaned by acetone with ultrasonic waves before assembling. Figure 8 schematically shows the test apparatus. The load was applied on the ceramic shaft after maintaining the given temperature for $10 \mathrm{~min}$. The sliding force at the inner interface (i.e., the limit value of the axial force when the sliding between the shaft and the shrink fitter initiates) was measured. The shear strength of the assembly was calculated by dividing the sliding force by the apparent contact area of the inner interface.

The sliding forces were observed from room temperature to $600^{\circ} \mathrm{C}$ in the heating and cooling processes. If the measurement of the shear strengths for R.T. (room temperature) to $600^{\circ} \mathrm{C}$ to R.T. is

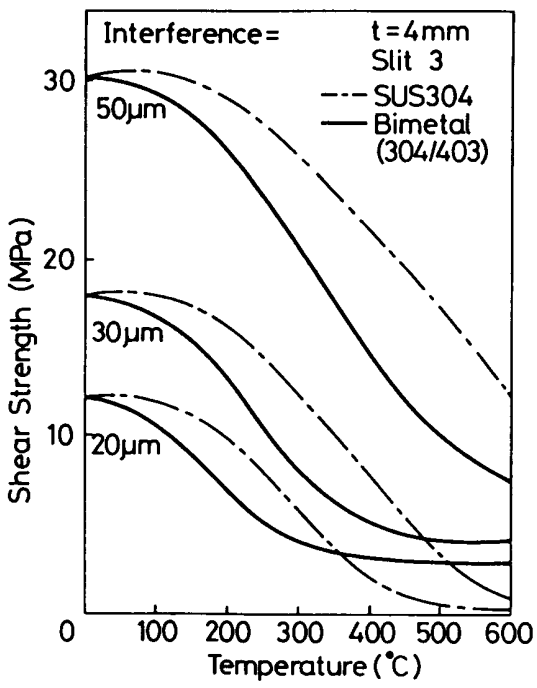

Fig. 7 Relationships between the shear strength and the temperature (comparison between the shrink fitters of the BO type and the SUS304 monolithic type for the various interferences; number of slits, $3 ; \mathrm{Al}_{2} \mathrm{O}_{3}$ ) 
referred to as a cycle of the measurement, the experiments with the same assembly were performed over two cycles. The shear strengths in the first cycle occasionally scattered but there was less scatter in the shear strength over the second cycle. The shear strengths in the second cycle were on a level with or somewhat lower than those in the first cycle. The shear strengths over the second cycle were of approximately the same level. The shear strengths in the second cycle were used to show the experimental results because it is safe to use the lower strength value for designing structures.

\section{Experimental Results}

\section{1 Hysteresis}

Figure 9 shows the shear strength-temperature relationship in one cycle, where the number of slits was 3 and the shrink fitter was of the BO type. Circles

Table 1 Shapes and dimensions of the shrink fitter and the outer rings

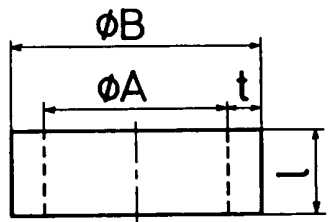

\begin{tabular}{|c|c|c|c|c|c|c|c|}
\hline \multicolumn{3}{|c|}{ Bimetal ShrinkFitter } & \multicolumn{3}{|c|}{ Outer } & \multicolumn{2}{c|}{ Ring } \\
\hline A & B & t & 1 & A & B & t & 1 \\
\hline 25 & 29 & 2 & 10 & 29 & 40 & 55 & 10 \\
\hline 25 & 33 & 4 & 10 & 33 & 44 & 5.5 & 10 \\
\hline 25 & 33 & 4 & 25 & 33 & 44 & 55 & 25 \\
\hline
\end{tabular}

Table 2 Material properties of the specimens to be shrink-fit

\begin{tabular}{|c|c|c|c|}
\hline & $\begin{array}{c}\text { Young's } \\
\text { Modulus } \\
\left(\mathrm{MPa}, 20^{\circ} \mathrm{C}\right)\end{array}$ & $\begin{array}{c}\text { Poisson's } \\
\text { Patio }\end{array}$ & $\begin{array}{c}\text { Coeff.ofThermal } \\
\text { Expansion } \\
\left(0-648^{\circ} \mathrm{C}\right)\end{array}$ \\
\hline $\mathrm{Al}_{2} \mathrm{O}_{3}$ & $3.14 \times 10^{5}$ & 0.235 & $7.6 \times 10^{-6}$ \\
\hline $\mathrm{Si}_{3} \mathrm{~N}_{4}$ & $3.04 \times 10^{5}$ & 0.27 & $3.0 \times 10^{-6}$ \\
\hline $\mathrm{SUS}_{304}$ & $1.93 \times 10^{5}$ & 0.30 & $18.8 \times 10^{-6}$ \\
\hline $\mathrm{SUS} 403$ & $2.00 \times 10^{5}$ & 0.30 & $11.7 \times 10^{-6}$ \\
\hline
\end{tabular}

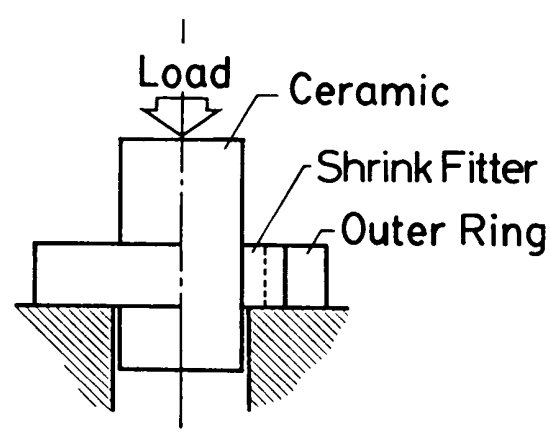

Fig. 8 Test apparatus for measuring the shear strength of the shrink-fitted assembly in outline and solid circles in the figure correspond to the heating and cooling processes, respectively. The shear strengths in the heating process rapidly decreased with temperatures from room temperature to $300^{\circ} \mathrm{C}$ and slightly decreased with temperatures from $300^{\circ} \mathrm{C}$ to $600^{\circ} \mathrm{C}$. The shear strengths in the cooling process increased linearly with decrease in temperature. The hysteresis phenomena were observed in all experiments, regardless of the BO or BI types. The obvious hysteresis phenomena were not observed in the previous paper ${ }^{(5)}$ using the monolithic SUS304 shrink fitter. Then the experiments of the assembly using the monolithic SUS304 shrink fitter with the same dimensions in Fig. 9 were performed and similar hysteresis phenomena were observed. It was thought that these hysteresis phenomena were related to the coefficients of the friction at the interfaces and to the dimensions of the assembly. Hereinafter, experimental data in the heating process were used to show the results.

\section{2 Effect of the thickness of the shrink fitter in} the radial direction on the shear strength

Figure 10 shows the experimental results of the assemblies with the thicknesses $t$ in the radial direction : $4 \mathrm{~mm}$ and $2 \mathrm{~mm}$ where the number of slits was 3 and the shrink fitter was the BO type. The shear strength with $t=4 \mathrm{~mm}$ was larger than that with $t=$ $2 \mathrm{~mm}$ at elevated temperature as the calculation predicted. It is thought that this experimental result was due to the lesser deformation force of the shrink fitter of $t=2 \mathrm{~mm}$ although the amount of curviform deformation of the shrink fitter of $t=2 \mathrm{~mm}$ was larger than that of the shrink fitter of $t=4 \mathrm{~mm}$.

It is also thought that these experimental results were due to interference of the assembly with $t=$ $4 \mathrm{~mm}$, which was $6 \mu \mathrm{m}$ larger than that of the assembly

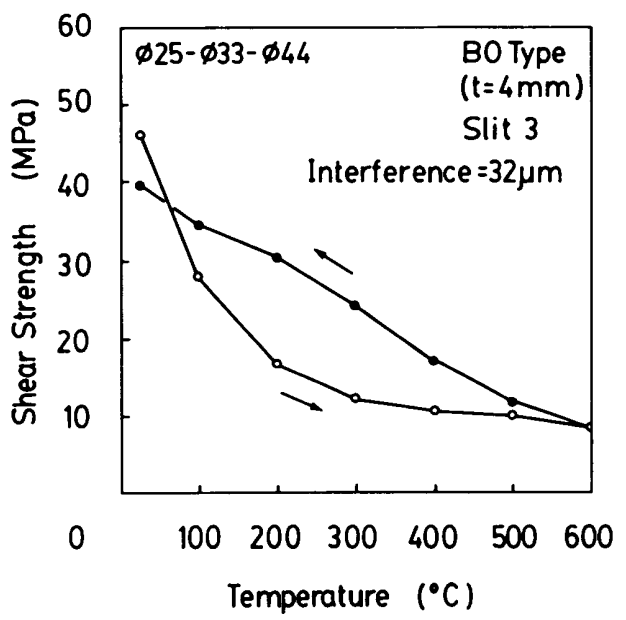

Fig. 9 Relationship between the shear strength and the temperature (hysteresis in one cycle of the experiment; circles, in the heating process ; solid circles, in the cooling process) 
with $t=2 \mathrm{~mm}$. The differences in dimensions between the diameters of the shafts and the inner diameters of the outer rings from $20^{\circ} \mathrm{C}$ to $600^{\circ} \mathrm{C}$ were $110 \mu \mathrm{m}$ and 85 $\mu \mathrm{m}$ for $t=4 \mathrm{~mm}$ and $t=2 \mathrm{~mm}$ respectively; that is, the diameter of the outer ring expanded much more than did that of the shaft. Taking account of this fact, it is thought that the $6 \mu \mathrm{m}$ difference in interference at room temperature did not greatly affect the shear strength at $600^{\circ} \mathrm{C}$.

\section{3 Comparisons between the $\mathrm{BO}$ type and the BI type}

Figure 11 shows the shear strengths of the assem. blies using the shrink fitters of the $\mathrm{BO}$ type and the $\mathrm{BI}$ type, respectively, where the number of slits was 3 and the thickness $t$ in the radial direction was $4 \mathrm{~mm}$. In Fig. 11, there are the strongest assembly using the BI type and the weakest assembly using the BO type. In comparison with other experimental results, the assemblies using the $\mathrm{BI}$ type were approximately 1 $\sim 2 \mathrm{MPa}$ stronger than those using the $\mathrm{BO}$ type at 600 ${ }^{\circ} \mathrm{C}$. It is thought from those facts that the assemblies using the $\mathrm{BI}$ type were slightly stronger than those using the BO type at elevated temperature for $t=4$ $\mathrm{mm}$. For $t=2 \mathrm{~mm}$, there were no meaningful differences in shear strengths between the $\mathrm{BI}$ and $\mathrm{BO}$ types. This was, as mentioned in section 6.2 , because of the lesser deformation force for $t=2 \mathrm{~mm}$. Figure 12 shows the shear strengths of the assemblies using the shrink fitters of the BO type and SUS304 monolithic type. The assembly using the BO type gradually grew stronger than that using the monolithic type over 400 ${ }^{\circ} \mathrm{C}$ and was $3 \mathrm{MPa}$ stronger at $600^{\circ} \mathrm{C}$. It is shown that the bimetal shrink fitter was effective to strengthen the assembly at elevated temperature, although the value of $3 \mathrm{MPa}$ would not be so great different. When comparing the assembly using the BI type with that

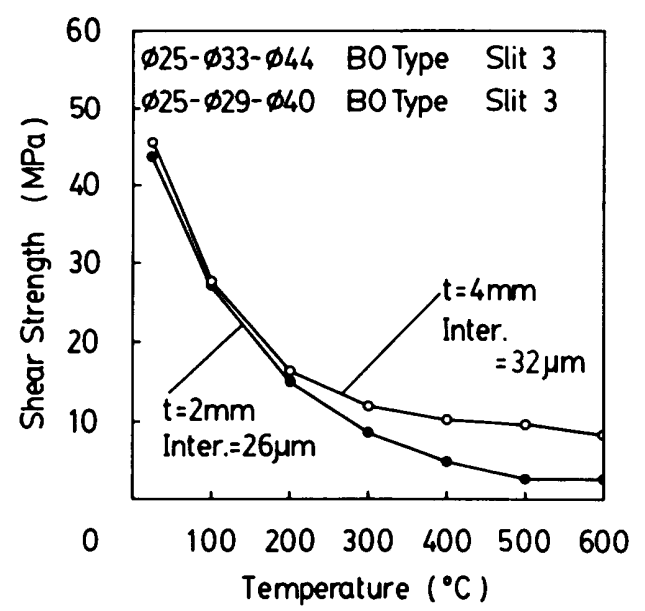

Fig. 10 Relationships between the shear strength and the temperature (for the various thicknesses of the shrink fitter in the radial direction, $\mathrm{Al}_{2} \mathrm{O}_{3}$ ) using the monolithic type, there was a greater difference in shear strength at $600^{\circ} \mathrm{C}$.

\subsection{Effect of the number of slits on the shear strengths}

Figure 13 shows the shear strengths of the assemblies with 1,2 and 3 slits. Because the interference of the assembly with 2 slits was less than those of other assemblies, this assembly could not be directly compared with the other assemblies. It can be seen from Fig. 13 that the assembly with 3 slits was stronger than that with 1 slit at the same temperature regardless of their interference at room temperature. For the monolithic SUS304 shrink fitter, the shear strength of the assembly with 1 slit was zero over approximately $400^{\circ} \mathrm{C}$. Thus the assemblies using the bimetal shrink fitters were not greatly affected by the number of slits compared with those using the monolithic shrink fitters.

\subsection{The shear strength using the $\mathrm{Si}_{3} \mathrm{~N}_{4}$ shaft}

Figure 14 shows the shear strengths of the assem-

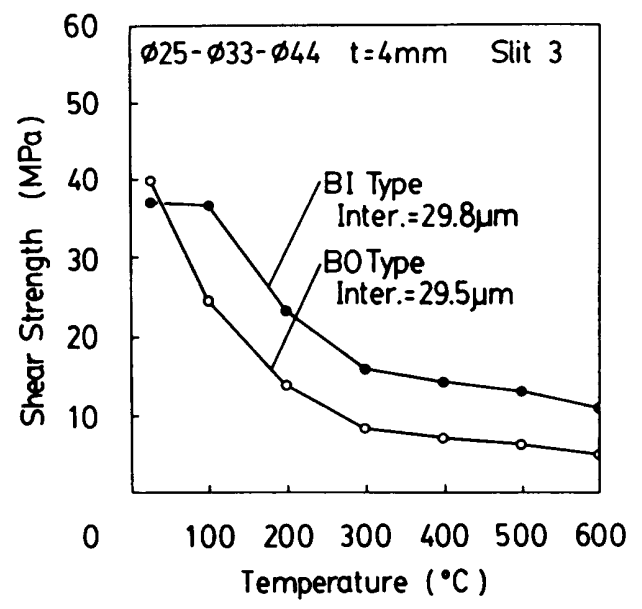

Fig. 11 Relationships between the shear strength and the temperature (comparison between the $\mathrm{BO}$ and $\mathrm{BI}$ types, $\mathrm{Al}_{2} \mathrm{O}_{3}$ )

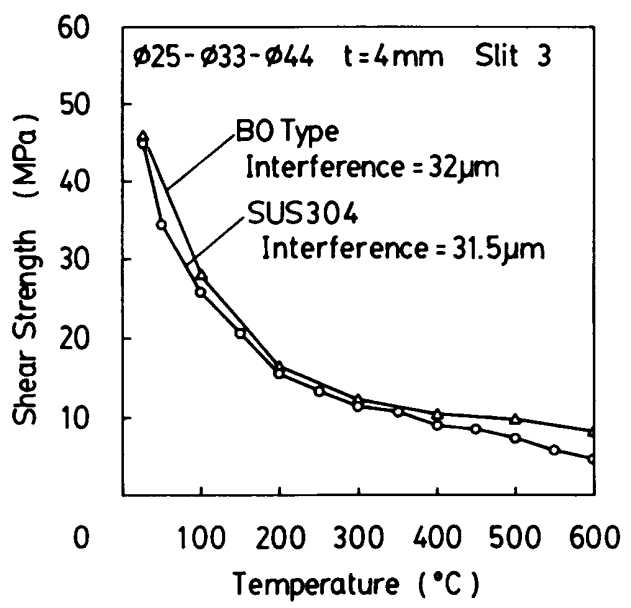

Fig. 12 Relationships between the shear strength and the temperature (comparison between the $\mathrm{BO}$ type and the SUS304 monolithic type, $\mathrm{Al}_{2} \mathrm{O}_{3}$ ) 
blies using the $\mathrm{Al}_{2} \mathrm{O}_{3}$ and $\mathrm{Si}_{3} \mathrm{~N}_{4}$ shafts. The shear strength of the assembly using the $\mathrm{Si}_{3} \mathrm{~N}_{4}$ shaft was zero at approximately $400^{\circ} \mathrm{C}$. This experimental result was understandable because the coefficient of thermal expansion of $\mathrm{Si}_{3} \mathrm{~N}_{4}$ is approximately half that of $\mathrm{Al}_{2} \mathrm{O}_{3}$. Then another experiment was carried out with an axial length of the shrink fitter of $25 \mathrm{~mm}$ in order to increase the amount of the curviform deformation. Figure 15 shows the corresponding experimental result. The shear strengths decreased with temperature up to $200^{\circ} \mathrm{C}$ similarly as in Fig. 14, but were constant over $200^{\circ} \mathrm{C}$. The shear strength was $2 \mathrm{MPa}$ at $600^{\circ} \mathrm{C}$.

\section{Discussion}

It can be seen from Fig. 12 that the assembly using the bimetal shrink fitter was somewhat stronger than that using the monolithic SUS304 shrink fitter at elevated temperature when the thickness of the shrink

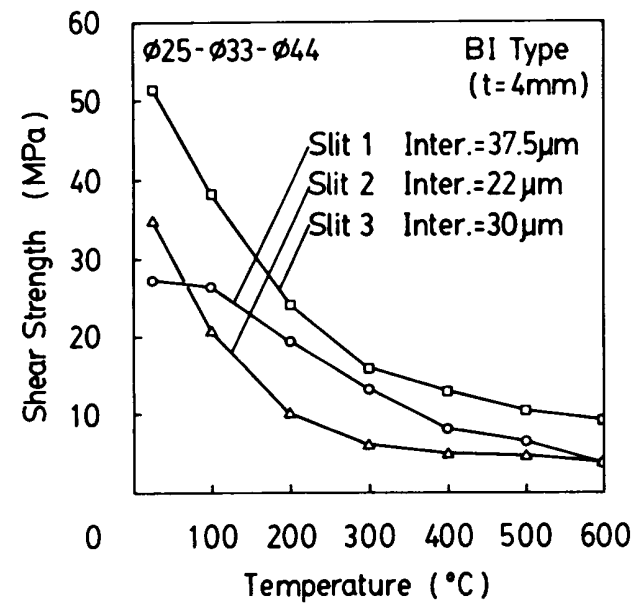

Fig. 13 Relationships between the shear strength and the temperature (for various numbers of slits, $\mathrm{Al}_{2} \mathrm{O}_{3}$ )

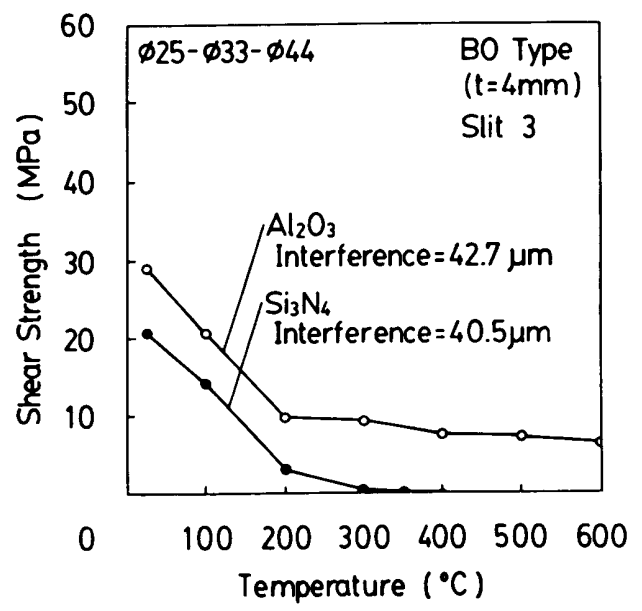

Fig. 14 Relationships between the shear strength and the temperature (comparison between the $\mathrm{Si}_{3} \mathrm{~N}_{4}$ and $\mathrm{Al}_{2} \mathrm{O}_{3}$ shafts) fitter in the radial direction was $4 \mathrm{~mm}$. Then we consider the contribution of the curviform deformation to the shear strength. We use simplified expressions derived in the prevlous paper ${ }^{(5)}$ for this purpose.

A dashed line in Fig. 16 shows the shear strengthtemperature relationship for the monolithic SUS304 shrink fitter. An alternate long and short dash line shows the same relationship for the shrink fitter of the BO type which is not brazed, that is, two rings of SUS304 and SUS403 which have slits and a thickness of $2 \mathrm{~mm}$ for each ring in the radial direction. Thus the amounts of thermal expansion of the shrink fitters in the radial direction make up for the decreases in the interference at elevated temperature for the dashed line and the alternate long and short dash line. The shear strength for the alternate long and short dash line is less than that for the dashed line at elevated temperature because the amount of the thermal expansion for the alternate long and short dash line in the radial direction is lesser than that for the dashed line. The shear strength using the bimetal shrink fitter is therefore certainly less than that using the monolithic shrink fitter at elevated temperature if only the thermal expansions in the radial direction are considered. The shear strength using the bimetal shrink fitter was, however, somewhat higher than that using the monolithic shrink fitter in the experiments.

A solid line in Fig. 16 shows the shear strengthtemperature relationship which was presumed from the experimental results using the shrink fitter of the BO type in Fig. 12. It is thought that the difference in the shear strengths between the solid and the dashed lines is due to the curviform deformation of the bimetal. It can be seen that mechanisms to improve the shear strengths at elevated temperature using the monolithic and bimetal shrink fitters differ from each other although their shear strengths did not differ so

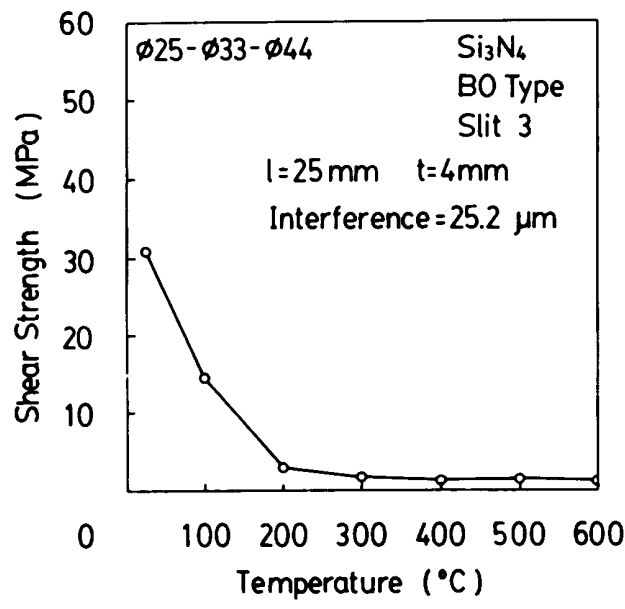

Fig. 15 Relationship between the shear strength and the temperature (for $25 \mathrm{~mm}$ in axial length of the bimetal shrink fitter, $\mathrm{Si}_{3} \mathrm{~N}_{4}$ ) 


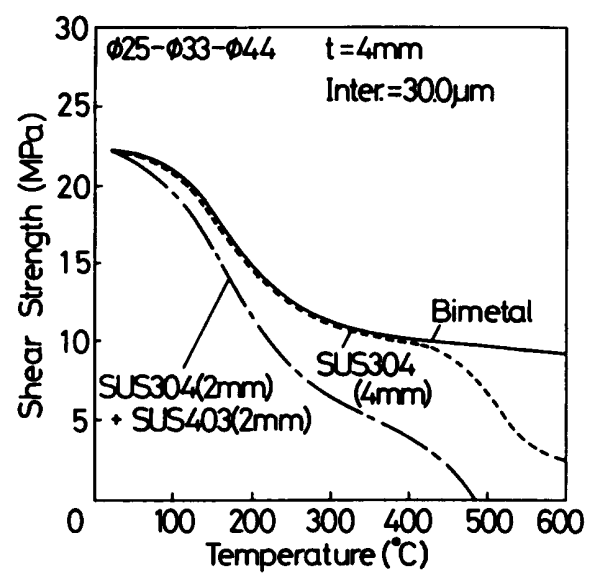

Fig. 16 Relationships between the shear strength and the temperature (contridution of the curviform deformation to the shear strength)

greatly. It is accurately predicted that the shear strength of the assembly using the bimetal shrink fitter would not decrease over $600^{\circ} \mathrm{C}$ from the considerations mentioned above.

\section{Conclusions}

In this paper, the shrink fits between the ceramic shafts and the metal rings using the bimetal shrink fitter were studied at elevated temperature in order to decrease the thickness of the shrink fitter in the radial direction, $t . \mathrm{Al}_{2} \mathrm{O}_{3}$ and $\mathrm{Si}_{3} \mathrm{~N}_{4}$ were used for the shafts of $25 \mathrm{~mm}$ in diameter. Conditions under which the use of the bimetal shrink fitter is better for stronger assembly were discussed through the experiments and the calculations.

The following results were obtained.

(1) The assembly using the bimetal shrink fitter was $3 \mathrm{MPa}$ stronger than that using the monolithic SUS304 shrink fitter at $600^{\circ} \mathrm{C}$ for $t=4 \mathrm{~mm}$.

(2) In the comparison between the $\mathrm{BO}$ and $\mathrm{BI}$ types, the assembly using the BI type was slightly stronger at elevated temperature for $t=4 \mathrm{~mm}$, but there was no meaningful difference in strength for $t=$ $2 \mathrm{~mm}$.

(3) The assembly using the bimetal shrink fitter of $t=4 \mathrm{~mm}$ was stronger than that of $t=2 \mathrm{~mm}$ at elevated temperature.

(4) The assembly using the bimetal shrink fitter with 3 slits was stronger than that with 1 slit.

(5) The shear strength-temperature relationship using the shrink fitter showed the hysteresis phenomena in which the shear strengths in the heating and cooling processes differed from each other.

(6) The shear strength of $2 \mathrm{MPa}$ was obtained at $600^{\circ} \mathrm{C}$ by making the length of the shrink fitter in the axial direction $25 \mathrm{~mm}$.

(7) The bimetal shrink fitter of which the thickness ratio of SUS304 to SUS403 in the radial direction was approximately $1: 1$ gave the strongest assembly at $600^{\circ} \mathrm{C}$.

\section{Acknowledgment}

The authors thank Professor Koji KATO of Tohoku University for his valuable discussions and Mr. Eiki KIMURA and Mr. Yoshitaka SUGIYAMA for their experimental and calculative assistances. This study was supported in part by a Grant-in-Aid for Scientific Research No.63750136, 1988, from the Ministry of Education, Science and Culture, Japan.

\section{References}

(1) Langer, M. and Stuart,P., Numerical Simulation of the Assembly of a Ceramic Swirl Chamber into a Metallic Housing, Ceramic Materials and Components for Engines, (1986), p. 1109.

(2) Ogawa, Y., Ogasawara, T., Machida M., Tsukawaki, Y. and Shimono, K., Complete Ceramic Swirl Chamber for Passenger Car Diesel Engine, SAE Tech. Pap. Ser., No. SAE 870650, (1987), p. 242.

(3) Miyauchi, J. and Kobayashi, Y., Development of Silicon Nitride Turbine Rotors, SAE Tech. Pap. Ser., No. SAE 850313, (1985), p. 30.

(4) Miyata, H., Iijima, S., Ooshima, R., Abe, T., Hisamatsu, T. and Hamamatsu, T., Application Technology on Ceramics for Structural Components of High Temperature Machines, Trans. Jpn. Soc. Mech. Eng. (in Japanese), Vol. 54, N0. 505, A (1988), p. 1700.

(5) Nitta, I., Kigoshi, K. and Kato, K., Study of the Fitting Strength Between Ceramic and Metal Elements with the Use of a Shrink Fitter at Elevated Temperature (Proposal of the ShrinkFit Method with the use of a Shrink Fitter and Experimental Results), JSME International Journal Series III, Vol. 32, No. 4 (1989), p. 632.

(6) Sugai, S., Mori, F. and Kuze, T., Development of the Technology of Bimetal, Metals \& Technology; Kinzoku (in Japanese), Vol. 55, No. 5 (1985), p. 34.

(7) Ootani, N., Assembly Between Geramic and Metal Elements, Japan Patent Journal (in Japanese), No.62-119178 (1987), p. 425.

(8) Nitta, I. and Hara, T., Study of the Fitting Strength Between Ceramic and Metal Elements with the Use of a Shrink Fitter at Elevated Temperature (Calculation of the Distribution of the Contact Pressure), Trans. Jpn. Soc. Mech. Eng.(in Japanese), Vol. 55, No. 520, C(1988), p. 3062. 